\title{
EL BUEY EN EL IMAGINARIO Y LA LITERATURA COSTARRICENSES
}

\author{
Ronald Campos López*
}

\begin{abstract}
RESUMEN
En este artículo se presenta el doble abordaje de la imagen del buey: pasividad estoica y destino trágico, tanto en el imaginario colectivo (textos pictóricos, orales, plásticos) como en la literatura (textos narrativos y poéticos) costarricenses. Se llega a una tercera visión, en el poema "El buey", de Laureano Albán, en el cual se expresa una vivencia cotidiana de lo sagrado por medio de la contemplación de este animal. Palabras clave: Buey, literatura, arte, imaginario colectivo, Costa Rica.
\end{abstract}

\section{ABSTRACT}

This article presents the dual approach to the image of the ox: stoic passivity and tragic fate, in the collective imagination (pictorial, oral, and plastic texts) and Costa Rican literature (narrative and poetic texts). The reader reaches a third view in the poem "The Ox" by Laureano Alban, which expresses the daily experience of the sacred through the contemplation of this animal.

Key Words: Ox, literature, art, collective imagination, Costa Rica.

\section{1. ¡Jesa ${ }^{1}$, jesa, buey...!}

El boyeo surge como parte de las labores agrícolas costarricenses durante el período colonial, posterior a 1561, "con la introducción del ganado vacuno y la carreta por parte de los conquistadores españoles" (Chang 2009a: 67). $\mathrm{Su}$ apogeo se dio en el siglo XIX y su declive, en el siglo XX (Chang 2009a, 2009b), debido al desarrollo tecnológico presente, de modo paulatino, en la capital, mediante el uso del tranvía eléctrico, a partir de 1899, y la habilitación de carreteras e incorporación de automóviles en 1916. En consecuencia, la tríada significativa de la carreta, los bueyes y el boyero (Chang 2009a, 2009b) pasó a adquirir mayormente un significado simbólico y artístico.

Si bien es cierto no es exclusivo de Costa Rica, el boyeo se apropió y resemantizó al adaptarse $^{2}$ al contexto histórico, sociocultural y ambiental de este país (Chang 2009a, 2009b). El patrimonio cultural ${ }^{3}$ de esta práctica abarcó tanto el desarrollo económico y cultural (Chang 2009), así como social, político, simbólico e histórico de Costa Rica.

Poeta costarricense, máster en literatura latinoamericana, docente en la Universidad de Costa Rica, Universidad Internacional de las Américas y el Instituto de Educación Integral.

Recepción:13/03/12. Aceptación:08/10/12. 
Durante el siglo XIX, se dio la conformación del Estado nacional costarricense y las reformas liberales, acompañada simultáneamente por el surgimiento de la oligarquía cafetalera ${ }^{4}$, su establecimiento como clase dominante y la centralización política ${ }^{5}$ del poder (Rojas y Ovares 1995, Quesada 2000). En este entorno de cambios económicos y sociales, la carreta fue utilizada para transportar "los materiales necesarios para la edificación de diversas obras en ciudades y pueblos como puentes, escuelas, iglesias y edificios públicos" (Zegarra y Fernández 2010b: §3). Por este medio se cargaron, verbigracia, la piedra granito para la construcción del Teatro Nacional, entre 1890 y 1897; las piezas metálicas para la iglesia neogótica de Vázquez de Coronado, Patrimonio Histórico Arquitectónico ${ }^{6}$, entre 1930 y 1937; los rieles para la vía del ferrocarril hacia Limón y la primera locomotora de Alajuela, en 1872. En las cuatro situaciones anteriores, los materiales fueron jalados por bueyes desde el muelle de Puntarenas; se tardaba entre cuatro o doce meses para cumplir con el arrastre.

A la luz de esto, léanse, respectivamente, la referencia de Stewart y la cita del periódico $E l$ Ferrocarril $^{7}$, esta última registrada por Murillo, sobre la llegada de la primera locomotora a Alajuela:

Cinco locomotoras de primera calidad fueron fabricadas en Paterson, Nueva Jersey, y fueron entregadas en Nueva York durante enero y febrero siguientes; una debíase embarcar a Puntarenas para la sección de Alajuela. ¡He aquí otra proeza que deberian realizar Juan Solano y sus bueyes ${ }^{8}$ ! (1967: 31)

No es de sorprenderse que un pueblo como el Costarricense, que no tiene mayores gustos que los triunfos de la paz i los provechos del trabajo i del comercio hayan visto con entusiasmo la primera locomotiva, jalada por bueyes desde la costa del Pacífico ${ }^{9}$, entrar por las calles de Alajuela á una altura de 4,200 piés sobre el nivel del mar (1995: 25).

Chang sintetiza, entre tanto, la indispensabilidad de la carreta y los bueyes, durante el siglo XX: como medio para transportar la madera con la que se construyeron la mayoría de las iglesias del Valle Central y de la Zona Norte, como medio de transporte para el paseo dominical ${ }^{10}$; para asistir a la fiesta patronal; como ambulancia y hasta carroza fúnebre ${ }^{11}$, como la han atestiguado varias personas y como ha sido representado en la literatura y en la plástica. En algunas zonas rurales se mantiene el uso tradicional para la siembra y la cosecha (de café, maíz, tabaco, caña, tamugas ${ }^{12}$, etc. ), pues resulta funcional en terrenos escarpados, en donde no entra el tractor. En Guanacaste, continúa su uso para el acarreo de arena, piedra y madera ${ }^{13}$. En los últimos años, ha cobrado fuerza en los desfiles de boyeros y carretas. Si bien estos no son una novedad, ya que han sido expresión de la religiosidad popular en procesiones de las fiestas patronales, en la última década su realización ha implicado la configuración de una serie de redes sociales, por lo que podemos concebirlo como una alternativa para que los boyeros, yuntas y carretas no se pierdan en la memoria colectiva. En suma, la imagen de la tríada es parte de la historia de muchas familias costarricenses, que ha sido utilizada como emblema nacional - y por endereferente identitario (2009a: 67).

Dentro de este marco histórico y cultural, el boyero y su carreta jalada por bueyes constituyen un elemento representativo del imaginario colectivo costarricense. La recreación del ámbito rural se construye sobre la imagen costumbrista del boyero (Zegarra y Fernández 2010b) o, por extensión, de la tríada (Chang 2009a, 2009b). Dicha visión ideológica del ser costarricense se evidencia en expresiones lingüísticas como leyendas, cuentos, poemas, refranes, lexemas ${ }^{14}$ y textos visuales; en los cuales se evidencia al buey como "un símbolo de bondad, de calma, de fuerza apacible; de potencia de trabajo y de sacrificio" (Chevalier y Gheerbrant, 1988: 202).

La primacía de este simbolismo puede deberse a la relación particular entre el boyero y su yunta de bueyes, más allá de cualquier actividad laboral, ganadera y agrícola, ya que: "En Costa Rica, esta empatía entre el boyero y el buey, tiene un valor simbólico, surgido y desarrollado en medio de las vicisitudes de los pueblos a lo largo de la historia" (Chang 2009a: 66-67, 2009b: 108). 
En sí, en los textos literarios, pictóricos, plásticos y orales costarricenses, por mencionar a continuación, se observa una "imagen paradisíaca del universo costarricense ${ }^{15}$ " (Campos, 2006: 93); "una Costa Rica bucólica, idílica, pacífica y perfecta (Rojas y Ovares 1995: 63). Esta imagen se enuncia, pues, con "un sentimiento de nostalgia por un pasado bucólico, definiendo a Costa Rica como un oasis de paz y democracia, este costumbrismo nacionalista volvió sus ojos a una suerte de Edad de Oro" (Campos, 2006: 92), donde se idealizan, románticamente: "ciertas anécdotas, tradiciones y costumbres [...] campesinas que [representan] la ya mencionada «edad de oro», el paraíso perdido o a punto de perderse, de los valores y tradiciones nacionales" (Quesada, 2002: 48-49).

\section{2. ¡Buey rejego ${ }^{16} \ldots$...}

La imagen más productiva y arraigada en el imaginario colectivo costarricense es la del buey partidario de una pasividad estoica, en tanto animal "manso, silente, noble y laborioso" (Campos, 2006: 94), paciente y obediente sobre todo. Un animal inclusive al cual se le puede ofrecer gratitud por los frutos que ha permitido cosechar y recoger. Tal imagen se concretiza en la leyenda popular "La carreta sin bueyes" (s.f.), las novelas El primo (2011) de Jenaro Cardona, El moto de Joaquín García Monge (2001) y Juan Varela de Adolfo Herrera García (2000); los cuentos "La propia" de Manuel González Zeledón (2000); los poemas "Mercando leña" de Aquileo Echeverría (1998), "Tico" de Carlos Gagini (2006), "Romance de las carretas" de Julián Marchena (1989) y "La vaca” de Lisímaco Chavarría (2003); los grabados en madera "Buey" (1934) y "Buey negro" (1934), y el relato "En Heredia" de Francisco Amighetti (s.f.); los óleos "Domingueando" de Tomás Povedano y Arcos (1915) y "Camino polvoriento" (s.f.) de Pedro Ortiz; así como en algunos refranes populares y pinturas artesanales contemporáneas, cual la de Arana (2011), entre otros.

Por su parte, en la leyenda popular, se observa cómo los bueyes obedecen el mandato del representante de la iglesia católica, a pesar del ímpetu con que se dirigen hacia el templo y las intenciones, no suyas, pero ante las cuales reciben indulgencia, precisamente, por su obediencia. Asimismo, se evidencia el uso de la carreta y los bueyes para transportar a los difuntos, según lo acotaban Zegarra y Fernández (2010a). Dice el texto:

\footnotetext{
"La bruja dijo por las buenas o por las malas y al morir su hombre, «enyugó» los bueyes a la carreta y puso la caja con el cuerpo muerto, cogió su escoba, su machete y se encaminó al templo.

Los bueyes iban con gran rapidez pero al llegar a la puerta, el sacerdote les dijo «en el nombre de Dios paren», los animales hicieron caso, mas no la bruja la cual blasfemaba contra lo sagrado.

El sacerdote perdonó a los bueyes por haber hecho caso" (Anónimo s.f.: §5-7)
}

En el ámbito religioso costarricense, el buey ha sido gratificado, de manera indirecta, por su colaboración, docilidad y disposición para las cosechas, comercio y progreso. Es un animal que, como en la susodicha leyenda, ha demostrado obedecer fines nobles. La estatuilla de San Isidro Labrador junto a sus bueyes, carreta y arado se encuentra en la iglesia católica del cantón Vázquez de Coronado. Este es un sitio representativo para ejemplificar la servidumbre de los bueyes, pues ellos fueron utilizados en más de cincuenta yuntas (Zegarra y Fernández 2010b) en el acarreo de las piezas metálicas para la edificación de tal templo, al servicio de la comunidad y la religión. Véase la siguiente imagen:

FIGURA 1. San Isidro Labrador

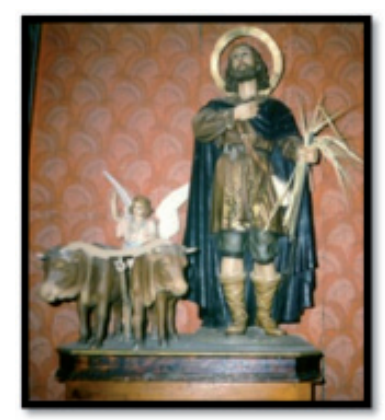


Dignos también de gratificación por su laboriosidad, apacibilidad y destreza, se muestran los bueyes en el cuento "La propia", en el cual ellos fueron partícipes activos en el desarrollo económico de la oligarquía cafetalera en Costa Rica. El vínculo con las labores en los beneficios de café, su utilidad cotidiana y recompensa se sintetiza en la descripción del siguiente fragmento:

En la sala, ñor Julián Oconitrillo, el dueño del beneficio y del cafetal y del cerco y del potrero y de la «bueyada» y de las sacas de leña y del trapiche del bajo y del cañal que lo rodea y del potro azulejo que en el caedizo se regodea con su buen cajón de pasto picado, atiende a la delicada tarea de la pesa de los sacos llenos, a la costura que sus hijos Bernabé y Zoila desempeñan y a la marca que Micaela su mujer les planta orgullosa con la lámina perforada «J. O. London» y la brocha untada de negrísimo betún. [...] Los mocetones alzan en vilo, con un vigoroso empuje de caderas, los sacos repletos y se los encajan en la membruda espalda y encorvados y haciendo resonar en el duro suelo sus talones de hierro, van tirando la carga en las carretas que el «bueyero» acomoda. Pela un muchacho con su afilado «Colis ${ }^{17}$ » las sabrosas cañas y partiéndolas en cabos, las ataruga en los hocicos de los bueyes, ya ocupados con el verde «cojollo» cuyas colas tiemblan a cada magullón de las poderosas quijadas... (González, 2000: 44-46)

Por otro lado, en El moto, se observa la pertenencia de los bueyes al patrimonio patriarcal, con el cual el hombre (José Blas, para efecto de la historia narrativa de este texto) debe contar necesariamente para conformar, proveer y transportar a la familia. Al respecto, léase:

“- Sí, padre. Pero a Ud. le costa que yo pa picar un trozo de leña —es feo decilo- me sobran juerzas; pa esmatonar o paliar — aunque es mala la comparación - me ando en un pie; tengo mi yuntica de bueyes sardos y pailetas aperadita y más que todo, Cundila me quiere mucho, pero muchísimo" (García, 2001: 32)

Este vínculo de los bueyes y el patrimonio patriarcal también se evidencia en otros tres momentos: Uno, con tono cómico, en el texto de Echeverría (1998), en el cual se reproduce una situación comercial cotidiana de los conchos ${ }^{18}$ costarricenses. Dos, con tono irónico, en medio de un contraste natural reverberante, en el momento cuando el protagonista Juan Varela debe abandonar con sus bienes y familia al haber sido embargada su propiedad (Herrera 2000); los bueyes aparecen enunciados sinecdóticamente por la carreta. Tres, con tono meramente referencial en el texto de Cardona (2011), cuando los campesinos dejan al cuido de otros (en este relato, una niña) los preciados bienes (la carreta y los bueyes). En la primera situación se observa el uso de la carreta y tales animales para transportar abastecimiento de madera (Zegarra y Fernández 2010a) en las zonas rurales; en la segunda, para cargar a la familia y los enseres en distintas oportunidades (Chang 2009a, 2009b; Zegarra y Fernández 2010a); en la tercera, han sido usados por los campesinos para llevar al Mercado Central y vender en él "cestos llenos de zapallos, de coles, de chayotes, de frutas, de esos mil artículos con que se surte aquel establecimiento para hacer frente a las necesidades de la capital" (Cardona, 2011: 132). En los textos de Herrera (2000) y Cardona (2011), se puede interpretar cómo, ante limitaciones económicas, las familias al menos contaban con los bueyes como recurso de trueque o negociación para solventar la situación financiera: "Para un campesino y su familia tener una carretas con bueyes era una inversión y un ahorro, así acumulaban dinero en caso de necesidad" (Zegarra y Fernández 2010a: §14). Bien sintetiza esto Cardona: "No sabés las crugías que yo paso pa juntar doscientos pesos; tiene uno que malbaratar una yunt'e bueyes o cuatro vacas..." (2011: 154).

Con base en lo anterior, considérense, a continuación, tres extractos de los textos citados:

Tal vínculo bueyes-patrimonio se representa en el óleo sobre tela, de Tomás Povedano y' Arcos, titulado: "Domingueando" (1915). En esta pintura se muestra el viaje de una familia campesina y sus bueyes por un paraje del Valle Central. Como costumbre, las familias de zonas tanto rurales como urbanas utilizaban 
CUADRO 1

Fragmentos de "Mercando leña" de Echeverría (1998),

Juan Varela de Herrera (2000) y El primo de Jenaro Cardona (2011)

\begin{tabular}{lll}
\hline “Mercando leña” & Juan Varela & El primo \\
\hline "Dígame, señora Chepa: & "Salida del terruño. Muy de mañana. & "Hacia el sur, en la Avenida Central, \\
¿no le gusta más pelada & Adelante, en la carreta, los chunches, la & había una porción de carretas enfiladas \\
y olorosa a yerbagüena, & mujer y los chiquillos. Atrás, a pie, Juan & de las cuales sacaban la panela envuelta \\
y con lazos en las puntas, & y Eduardo, el primogénito19. & en hojas de caña; cerca de una de aque- \\
y aspergiada de canela, & - ¡Yo no me quiero ir, papá! ¡Yo no me & llas carretas había una chiquilla bonita, \\
y que además le regale & quiero ir! & paliducha, cubierta con un pañoloncillo \\
como a modo de una feria, & Más que nunca cantaban los jilgueros & de lana a cuadros, y con un sombrero de \\
el chonete, los güeycillos, & esa mañana. El día anterior la veranera & pita sucio, que miraba a los transeúntes \\
los calzones, la carreta, & que había sembrado el año pasado ardió & con ojos atontados, y cuidaba de los bue- \\
y este chuzo, y esta faja, & en rojeces vivas." (Herrera, 2000: 43). & yes con el chuzo en la mano." (Cardona, \\
y’a la zonta de mi agüela?" & & 2011: 132). \\
(Echeverría, 1998: 79). & & \\
\hline
\end{tabular}

sus bueyes y carreta para visitar a otros grupos familiares; pasear en conjunto por el parque, la plaza o la calle principal del pueblo (los jóvenes aprovechaban este paseo para coquetear y toparse entre ellos). Las mujeres solían vestir enaguas largas; los hombres, sombrero, camisas manga larga, pañuelo rojo; ambos caminaban descalzos. En ocasiones, la carreta contaba con un toldo, para cubrir del sol o la lluvia ${ }^{20}$, y un cofre para guardar los vestidos del paseo. Las familias contaban hasta con tres yuntas en su patrimonio, máxime si se poseía un trapiche, donde el trabajo de los bueyes era indispensable (Morales 1986), y si resultaba simultáneamente necesario el transporte en otras diligencias. Como muestra de lo anterior léase:

Daba gusto oírle, por ejemplo, cuando hablaba de los viajes a Puntarenas, de aquellos legendarios viajes que nosotros hemos oído más de una vez relatar a nuestros abuelos, viajes que formaban época en los anales de la familia.

Era Puntarenas el único puerto por donde se hacía en los buenos tiempos del señor Ayala el comercio del país, y tales excursiones que realizaban casi todos los años las familias pudientes del interior [...]

Se calculaban las carretas que era menester contratar para el transporte de las señoras que no podían cabalgar, y de la gente menuda; luego en la confección de los trajes y de los sombreros a propósito para resistir aquellos soles y aquellas polvaredas; luego en la cesta del bastimento surtida con las mejores golosinas de nuestra industria [...] Después, salir de la ciudad con dos o tres carretas provistas de altos arcos y cubiertas de vistosos toldos de zaraza, rodeadas por los jinetes que llevaban a la grupa sendas alforjas, camino de La Uruca [...] (Cardona, 2011: 3)

De regreso al cuadro de Povedano y Arcos, en él la figura, la luz y "la coloración parduzca característica de una idealización de la naturaleza" (González 2007: 224) refuerzan, con un estilo neoclásico y romántico europeo, la imagen idílica del ser nacional de principios del siglo $\mathrm{XX}$, esa imagen construida $\mathrm{y}$ difundida por los ideales de los oligarcas y burgueses capitalinos (González 2007). En este cuadro se observa que: "La imagen de la tríada es parte de la historia de muchas familias costarricenses, que ha sido utilizado como emblema nacional y, por ende, referente identitario" (Chang 2009b: 109).

Al respecto, considérese la siguiente imagen:

FIGURA 2

"Domingueando" (1915), de Tomás Povedano y Arcos

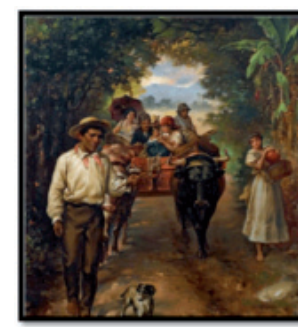


Como respuesta a esta herencia europea de la Generación Nacionalista de los años 30, instituida y tutelada justamente por Povedano y Arcos, los nuevos artistas costarricenses (entre ellos Teodorico Quirós, Fausto Pacheco, Juan Manuel Sánchez y Francisco Zúñiga), en concordancia con "las vanguardias artísticas europeas de principios del siglo XX" (Ulloa 2008: §3), rindieron interés a "lo autóctono y lo «primitivo» (así se decía entonces)" (Ulloa, 2008: $\S 3)$, como forma de recuperar lo nacional ${ }^{21}$.

Pedro Ortiz ${ }^{22}$, en su óleo sobre tela: "Camino polvoriento" (s.f.), plasma "el escenario donde se desarrollan las actividades diarias del labriego y donde este se integra a su entorno" (Ulloa, 2008: §10). En este cuadro, el devenir temporal se sugiere con el impresionismo plástico que se logra con los contrastes de luz y la intensidad de los colores verdes, cafés, amarillos, rosados y celestes. Podría afirmarse que: "El color del paisaje, léase la temporalidad, no solo influye en el ánimo, sino también en la percepción de la realidad que se abre ante [los] ojos [...] En tanto movimiento, el tiempo se concibe estrictamente como cambio y proceso, y el movimiento por excelencia se revela en el orden de la naturaleza, en los movimientos de los astros del cielo y el cambio de las estaciones" (Chen, 2007: 58). De ahí que en el texto de Ortiz: "Las labores de quienes se dedican a la tierra vienen determinadas por el paso del tiempo" (Ulloa, 2008: §11). El objetivo es traslucir "un profundo compromiso y una identificación con la vida y las costumbres de nuestros campesinos" (Ulloa, 2008: §9).

Ergo, en dicho paisaje crepuscular bucólico y costumbrista - aparece, tras finalizar su jornada, un boyero, montado sobre su carreta, mientras saluda a una mujer, ubicada cerca — quizás la suya - de la casa típica de adobe del siglo XVIII: otro símbolo del pasado de la estética y filosofía edénica costarricense.

Considérese la siguiente imagen:
FIGURA 3.

"Camino polvoriento" (s.f.), de Pedro Ortiz

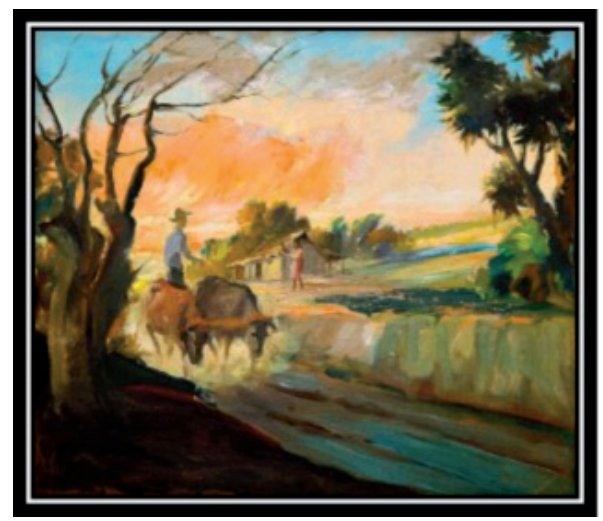

En los textos de Marchena (1989), Gagini (2006) y Amighetti (1934, s.f.), redunda el motivo de la mansedumbre, la nobleza y laboriosidad del buey.

En "Romance de las carretas", se construye el escenario idílico y bucólico donde el buey pace, solemne, paciente (tal cualidad se enuncia en este poema como en el refrán popular: "Se necesita tener esa paciencia de buey para...") y sereno ("se mueven siempre sin prisa,/ - tarde o temprano se llega-"), aguardando la luz de la mañana y el llamado ("cencerro") del boyero, para someterse deseoso y voluntario al yugo. Esta disponibilidad de someterse al boyero y su yugo, ante el cual el animal no parece incomodarse, también se presenta en la topografía paradisíaca del "tico": su vivienda, su trabajo, sus animales, su sentir compenetrado con la tierra, la naturaleza toda y sus labores campestres, que Gagini (2006) y Cardona (2011) construyen en sus textos. Resulta significativo el hecho de que tanto en el poema de Marchena (1989) como en el de Gagini (2006), y en la novela de Cardona (2011), la mañana o la aurora simbolizan el sometimiento del buey ante el despunte y la sucesión regular de la vida laboral.

Léanse los tres fragmentos: 
"De madrugada las yuntas que están rumiando a su vera, poco antes de ser uncidas clavan los ojos en ellas; su comprensiva mirada largo rato las contempla y al escuchar un cencerro, pausadamente menean el hisopo de la cola y con vaho las inciensan. Como una flor luminosa se abre la mañana espléndida." (Marchena, 1989:98)

“¡Con qué placer al despuntar la aurora iba a enyugar los bueyes al potrero"

(Gagini, 2006: 38)

"Después, los sesteos, las dormidas en las posadas donde siempre había gente aunque rústica, amable, confiada y servidora: levantarse a la madrugada, ver uncir los bueyes y ensillar las cabalgaduras a la luz de los luceros y contemplar la salida del sol desde lo alto del monte del Aguacate" (Cardona, 2011: 3)

En el texto de Marchena (1989), por medio de metáforas impresionistas ${ }^{23}$, se procede a describir a la carreta y sus bueyes, enfatizando su utilidad en actividades cotidianas como el transporte de enfermos, productos y mercancías agrícolas; asociadas con matrimonios, vivienda y trabajo; ya en un espacio campestre ("polvo"),

FIGURA 4

"Buey", de Amighetti (1934) difícil de transitar ("barro") o rocoso ${ }^{24}$, sobre el cual se anuncia el sonido de sus ruedas ("agudo violín, chirriando,/ grave tambor, en las piedras”). Al respecto, véase:

\author{
"Ambulancias campesinas \\ hormigas de las cosechas, \\ cándidos lechos nupciales \\ y trashumantes viviendas, \\ se mueven siempre sin prisa, \\ - tarde o temprano se llega-, \\ y sobre el polvo o el barro \\ detrás de sí sólo dejan, \\ como las almas afines, \\ ondulantes paralelas.

\section{$[\ldots]$} \\ $\mathrm{y}$, quejumbrosas y a tumbos, \\ enfílanse las carretas, \\ -agudo violín, chirriando, \\ grave tambor, en las piedras-_" \\ (Marchena, 1989: 98-99)
}

Los grabados en madera "Buey" y "Buey negro" de Amighetti (1934) sintetizan esa idea e imagen de nobleza ejemplarizante del buey en el ambiente pastoril y a mitad de una faena, donde tampoco el yugo parece afectar su temperamento. El mismo Amighetti (s.f.) reproduce esta visión idílica en su discurso

FIGURA 5

"Buey negro", de Amighetti (1934)

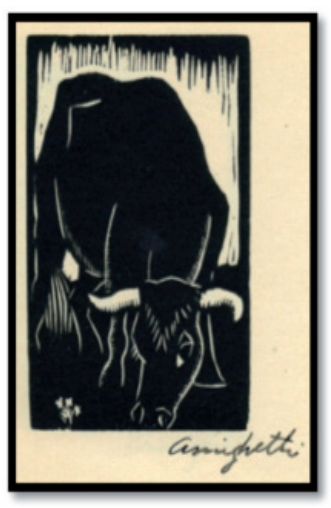

"En Heredia"

"Las pinté en los ríos cuando los campesinos con las piernas metidas en el agua las cargaban de arena; en penumbra donde el sol bombardeaba la piel de los bueyes y el agua negra, llena de sombra, se manchaba de oro. En mi infancia fui a los pueblos por caminos pedregosos en donde el único vehículo colectivo era la carreta y en ella asistí a los «turnos» olorosos a alcohol y llenos de gritos” (Amiguetti, s.f.: §6)

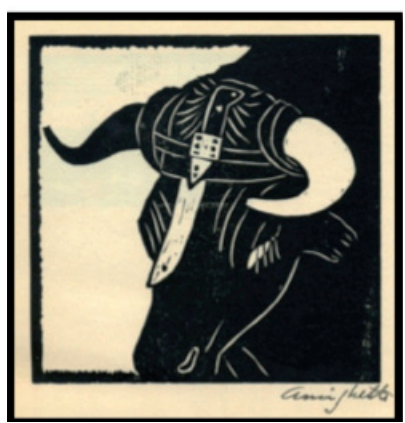


narrativo. Obsérvese de nuevo la relación del buey con lo solar. Compárense los tres textos de este autor:

En la actualidad, son frecuentes el diseño y la confección de piezas pictóricas o plásticas en cerámica, en las cuales se moldea a los bueyes, en el campo idílico, junto a la casa de adobe. Véase, por ejemplo, la siguiente figura:

\section{FIGURA 6}

Pintura en óleo: "Casa típica costarricense", de Gonzalo Arana Orono (2011)

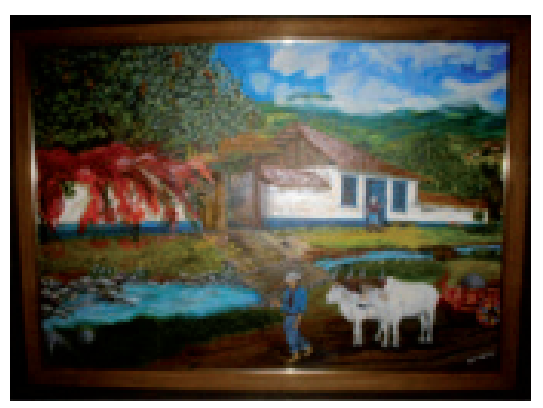

El poema "La vaca", de Chavarría (2003), reitera la mansedumbre de esta última criatura (se dice de ella, por ejemplo: "tienes la filosofía/ de ser mansa", p. 15, o "tú pasas dócil y mansa/ obedeciendo al vaquero", pp. 13-14) en cinco oportunidades; esta es extendida al buey, tal como lo indican los siguientes versos:

\footnotetext{
"Vaca, mansa compañera

de los nobles bueyes viejos

que saben de los afanes

de los fuertes jornaleros"

(Chavarría, 2003: 15).
}

De acuerdo con Campos, en el poema de Chavarría (2003), se construye el buey pretendiendo que sea la suya la misma "figura ejemplarizante [...] para el hombre costarricense: ser manso y pasivo, nunca valiente y viril" (2006: 94). Tal construcción del buey "se ubica totalmente dentro de este discurso oligárquico, promovido por el Olimpo nacional, que añoraba un pasado idílico donde el costarricense aceptaba, sin cuestionar, el régimen del cual estaba excluido [...un] ideal bucólico propuesto por el Olimpo literario para la identidad costarricense, en concordancia con un proyecto político nacional" (Campos, 2006: 95).

Este, en efecto, es el mismo discurso que, por un lado, se poetiza en el texto de Gagini (2006) y, por otro, se podría leer en el Himno Nacional de Costa Rica, cuando se entonan las siguientes estrofas. Estas dicen:

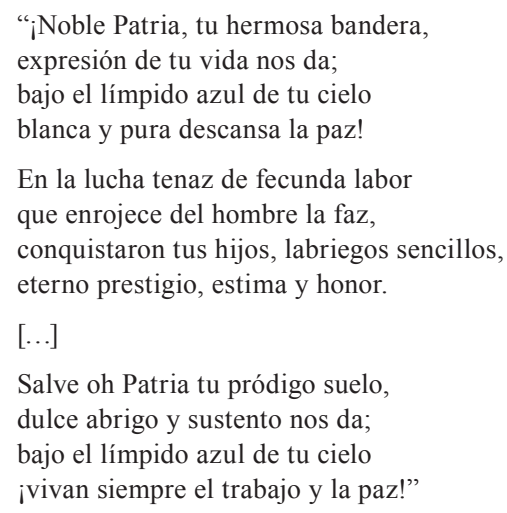

Las estrofas susodichas del Himno, este texto-monumento (Amoretti 1987), presentan una ecuación básica que funciona como referencia para la identidad del ser costarricense, trabajada en la propia literatura. Esta ecuación es: "paz + trabajo= crédito (riqueza y felicidad)" (Amoretti, 1987: 41). Amoretti (1987) observa que el trabajo se liga con las operaciones agrícolas, donde la única lucha permitida es aquella emprendida contra la tierra, con tal de obtener frutos ${ }^{28}$. De nuevo se presenta un sistema político, social y ético, en el cual el patrimonio familiar y el crédito se encuentran vinculados con lo telúrico.

Como se ha ejemplificado con los textos literarios anteriores, es en medio de este contexto de laboriosidad y labranza donde aparecen las figuras del boyero, el buey y la carreta, las cuales advertirían, principalmente la primera, un reflejo del sintagma nominal: "labriego sencillo".

Esta última es una frase clave de la autoimagen del costarricense (Amoretti 1987). Sobre ella recaen dos lecturas antagónicas, presentes desde la génesis del nacionalismo ${ }^{29} \mathrm{y}$ la narrativa costarricenses: la visión patriarcal y la liberal. La una considera la sencillez "como 
cualidad positiva o virtud: sencillo es humilde, pobre, inocente" (Amoretti, 1987: 65); por eso vincula aquel valor con una ética cristiana, según la cual la riqueza espiritual y la humildad son bienes que aseguran la convivencia social ideal. La otra escatima la sencillez, pues esta connota inferioridad: "ignorante, sinónimo de «polo», «maicero», «concho», «tonto»" (Amoretti, 1987: 65); de ahí que la humildad o sencillez sean negativas dentro de una ética mercantil, donde claramente la riqueza material es el fruto de la lucha y, por ende, del "triunfo".

Enfatizando, pues, más la segunda lectura de la frase "labriegos sencillos", se puede afirmar que la promoción de una Costa Rica ideal y bucólica, poblada de ciudadanos ("bueyes") mansos, nobles, sosegados, inocentes y conformistas es parte de una formación discursiva liberal, propia de la ideología imperante del Olimpo, sobre la cual se pretendió un imaginario colectivo c costarricense.

\section{3. ¡Buey pendejo...!}

Distinta de lo presentado hasta el momento en los susodichos textos, en cuentos como "El camino" de Carlos Salazar Herrera (1990), la novela El jaúl (1998) y el poema "Los dos bueyes" (2000) de Max Jiménez, se ofrece otra visión obediente del buey, pero esta vez no plácido a pesar de las labores que cumple, sino en medio de un paisaje adverso, de maltrato, de angustia (Jones 2005).

Si bien en el "Romance de las carretas" se presentan los chuzazos ${ }^{30}$ como forma de infligir a los bueyes fuerza, diligencia y constancia en las situaciones hostiles de la faena, ya por las condiciones del terreno, ya por un acto de deshago del estado anímico del boyero, tales golpes marcan la dirección y ritmo, a modo de armonía música con el sonido de las ruedas de la carreta sobre el camino empedrado, sin implicar nunca dolor. Véase, al respecto:

"y, quejumbrosas y a tumbos, enfílanse las carretas,

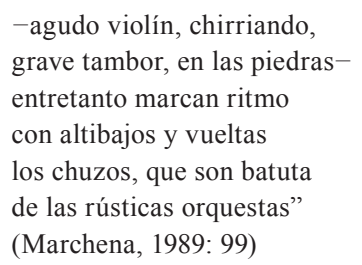

-agudo violín, chirriando, grave tambor, en las piedrasentretanto marcan ritmo con altibajos y vueltas los chuzos, que son batuta de las rústicas orquestas" (Marchena, 1989: 99)

No obstante, esta situación es distinta de la de los relatos de Salazar (1990) y Jiménez (1998). En "El camino", se construye todo un "paisaje de la angustia" (Jones, 2005: 53), en donde el espacio físico es vivificado por las prosopopeyas ${ }^{31}$. Los atributos animados se interpretan "como peligrosidad, movilidad, agudeza, luz, sombra, sonido/silencio. Todo ese universo engloba la posibilidad de caer, abismarse en alguno de los precipicios (irse de cabeza, según la etimología de esta palabra) que lloran soledades. La red de significantes construye una isotopía: una estructura caracterizada en sus polos por la vida/ la muerte" (Jones, 2005: 52). Esta descripción de los espacios de altura que debían cursar los bueyes se encuentra implícita en este relato, así como en la cita de Murillo (1995) y en la novela de Jiménez (1998), cuyo primer capítulo se titula "3000 metros".

Al respecto, léase:

"Por ese camino bajaba una carreta.

El boyero no podía detener a los bueyes que patinaban cuesta abajo, por el declive resbaladizo. [...]

Cayó de rodillas un buey. El impulso lo arrastró untándole el hocico de barro. El otro buey bufó un dolor de pescuezo que se hundió en la tierra. La carreta se ladeó chillando, junto a un paredón. [...]

Un chuzazo levantó al buey caído, y la carreta se echó a resbalar de nuevo, mordiendo la gravedad. [...]

Esta vez cayeron los dos bueyes, y sus cuatro ojos fosforecieron como carbunclos.

El boyero soltó una maldición que traía prensada entre los dientes.

Nuevas punzadas de chuzo hicieron levantarse a los bueyes" (Salazar, 1990: 161-162)

Es esperable que el buey tropiece o sucumba en tal camino. De hacerlo, el personaje del relato, quien funge como boyero, resuelve el 
accidente de un solo chuzazo. El animal siempre, sin importar las circunstancias, debe cumplir con su quehacer. Este atributo o demanda al buey se explicita en el refrán popular: "Al buey por el cacho y al hombre por el bigote". Este suele decirse cuando una persona debe acatar su palabra después de haberla empeñado.

Es redundante y significativo el hecho de que la descripción del escenario angustiante, desolado e intransitable se vea enfatizada mediante el simbolismo del barro ${ }^{32}$ en tanto este sugiere involución y degradación. En ambos textos, la lluvia se presenta como símbolo del escenario propicio para que los bueyes y su boyero sean sacrificados o avasallados, padeciendo su condición de campesinos y la adversidad, hasta el punto de enfrentarse con la muerte. Considérese:

\footnotetext{
"La lluvia...

La noche...

La lluvia se puso a rodar piedras al declive. [...]

El camino estaba hecho un río. [...]

El que murió fue el boyero." (Salazar, 1990: 161 y 163$)$

"La montaña se arruga en su maldición de desaparecer, lavada por las aguas incesantes, hasta convertirse en el ceño de las mujeres en pena. Las nubes pasan, enjugándole su trágica existencia. [...]

Los riachuelos, sucios por la constante llovizna, iban de huida. [...]

\begin{abstract}
Allí, más que en ninguna otra parte, la tierra parece decir que todo le pertenece [...] ya el buey gacho ${ }^{33}$ parecía pedirle perdón al Creador sobre las rodillas delanteras, la boca llena de espuma y las narices aventando la vida." (Jiménez, 1998: 17-19)
\end{abstract}

En "El camino", el protagonista se encuentra atormentado por las condiciones del medio que le impiden llevar pronto a su mujer al médico. A pesar de su sanidad, el protagonista involuciona debido a un percance con la yunta: esta resbala y le cae encima sobre el vientre. Al final, irónicamente, "el enfermo se salva y «el sano» se muere" (Jones, 2005: 54). En El jaúl, Chunguero sube ebrio la cuesta embarrialada y obliga a su yunta a que luchen contra tales condiciones, aun soportando los chuzazos arbitrarios y violentos que la embriaguez lo induce a darles. Parece que los animales lo mismo que su boyero se encuentran determinados por el medio ambiente a padecer la degradación a modo de un sarcástico sacrificio humano. Al respecto, léase el siguiente extracto:

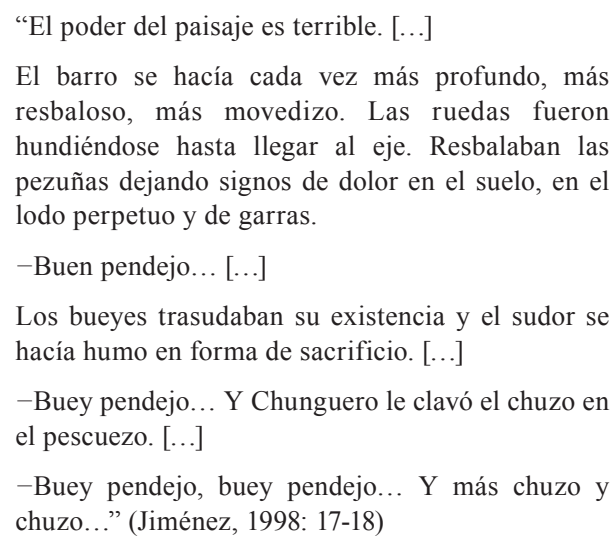
resbaloso, más movedizo. Las ruedas fueron hundiéndose hasta llegar al eje. Resbalaban las pezuñas dejando signos de dolor en el suelo, en el lodo perpetuo y de garras.

-Buen pendejo... [...]

Los bueyes trasudaban su existencia y el sudor se hacía humo en forma de sacrificio. [...]

-Buey pendejo... Y Chunguero le clavó el chuzo en el pescuezo. [...]

-Buey pendejo, buey pendejo... Y más chuzo y chuzo..." (Jiménez, 1998: 17-18)

Esta sumisión y pasividad del buey en medio del azote violento se presenta, asimismo, en "Los dos bueyes". Acá, este animal "es presentado como un pobre obrero explotado" (Campos, 2006: 98). Contrario al de Chavarría (2003), donde el buey "bucólico va manso a la fecunda labor" (Campos, 2006: 98), en este poema:

estos obreros son obligados a un excesivo y monstruoso trabajo que descarna sus frentes. Viven -literalmente- subyugados por un régimen que los oprime; son "víctimas de las leyes" que los explotan sin misericordia, maltratados por un amo que no es el campesino bueno de Chavarría, sino un verdugo, un hombre que ejecuta la condena que pesa sobre ellos: trabajar hasta que sean "astros apagados/sus ojos entornados" [...] Trabajar hasta el cansancio, hasta el dolor, hasta la muerte. (Campos, 2006: 98)

Es evidente una lectura del discurso del realismo socialista, promovido por la generación del Repertorio Americano, principalmente en la década de los 40. De acuerdo con lo anterior, considérense los siguientes versos:

"Están en el camino

víctimas de las leyes, 
los cuerpos extenuados, lamiéndose, dos bueyes

$[\ldots]$

Descarnadas las frentes por el peso del yugo, raída la osamenta por el leño del verdugo." (Jiménez, 2000: 43)

Campos (2006) rescata el hecho de que en este texto la yunta de bueyes sugiere la opresión emitida sobre un grupo. Ya no se trata de un buey independiente, cuya autonomía se recuerda en el refrán popular: "El buey solo se lame mejor". Ahora es visto como parte de un conjunto. Con base en esta lectura, Campos analiza, oponiendo siempre este texto con el de "La vaca" (Chavarría 2003), la figura del buey homologada a la del ser costarricense, pues ambos, "marginado[s] por un régimen [...semm niegan a] ese futuro bucólico que el Olimpo hubiera querido" (2006: 99): ese futuro idealizado que los oligarcas y el Olimpo en Costa Rica lucharon por difundir social, política y culturalmente.

Con sus ideales europeizantes y de progreso tecnológico y económico, la clase dominante josefina insistió en civilizar, marcando la separación de poderes (los controles centrales, regionales y cantonales), las condiciones de vida (entre oligarcas, burgueses comerciantes, gamonales, proletariado y campesinos) $\mathrm{y}$ artísticas (entre los modelos estéticos e ideales europeos y costarricenses ${ }^{34}$ ) (Botey y De la Cruz 1987). Dos ejemplos que sintetizan esta tensión, en los cuales el símbolo del buey se inmiscuye, son el cuento "Neurosis" de Ricardo Fernández Guardia (2004) y la novela El primo. En aquel cuento, se sobrevaloran los avances tecnológicos que llevarán a Costa Rica hacia un porvenir idílico, ya no basado y dependiente del trabajo rudimentario y obsoleto (los bueyes), sino en la modernidad (las máquinas). En la novela de Cardona (2011), se expresa, primero, cómo la presencia de lo rústico de las carretas y los bueyes afea y retada la posibilidad de convertir a San José en una ciudad cosmopolita, en el mismo nivel que París u otra metrópolis europea; y, segundo, cómo esta misma presencia de lo rústico se afianza degradantemente en el ser costarricense en general.

Al respecto, véanse las siguientes citas:

\begin{abstract}
“Observa lo perfecto que es todo esto -me decía alzando la voz a causa del ruido ensordecedor de las máquinas-. ¿Qué lejos estamos ya del filón de madera y de la trilla ${ }^{35}$ de bueyes! Cuatro hombres bastan ahora para hacer el trabajo" (Fernández, 2004: 73)
\end{abstract}

“-¡Oh! He pasado una tarde admirable; tomé una volanta y le he dado dos vueltas a La Sabana ¿Qué hermoso paseo! ¡Qué aire se respira allí! ¡Qué vistas! Aquellas cordilleras azules... todo es encantador No me explico cómo no se van allí las gentes en una tarde como la de hoy, a correr, a respirar... uno que otro paseante y algunas vacas y bueyes; ¡qué lastima! Cuánto se podría hacer allí; un bosque de Boulogne, un Hyde Park..." (Cardona, 2011: 65)

“-;Oh! No crea, y en nuestros días hay muchos que también toman la figura de un toro, y hasta la de un buey... salvo las cuatro patas y el rabo..." (Cardona, 2011: 71).

\section{Un fierro ${ }^{36}$ muy distinto para este otro buey...}

De acuerdo con Campos $(2012)^{37}$, en los dos últimos versos del poema "El buey", de Laureano Albán (1995), el apóstrofe logra evidenciar la autoidentificación y homologación - poetizadas a lo largo de todo el texto- del sujeto lírico con el buey, puesto que ambos comparten la misma sujeción temporal: el buey también es un recuerdo ("buey del ayer que pasas,/ subidor de mi infancia"); el sujeto lírico se encuentra como el buey también domeñado al tiempo, sin voluntad, en lo terrenal y profano, dentro de una lógica racional de pensamiento ("entre el barro y la niebla/ que en los ojos te humillan"). El sujeto lírico llega a ser consciente de esto ("la pesadez del yugo/ de todo lo que sé") ahora, cuando es el momento presente de los dos, pues ambos están solos, alzan los ojos, osan mirar más allá, sienten el pasado atrás, gritan a Dios, van a la tierra, alzan las manos. La conjunción coordinante copulativa "y" que abre 
cada anáfora y conversión ${ }^{38}$ sugiere la existencia de otras situaciones anteriores o razones previas que el sujeto lírico y el buey también comparten, pero que para efectos del poema no han sido enunciadas.

Léase la última estrofa de este poema:

"Te entiendo[,] ${ }^{39}$ compañero,
buey del ayer que pasas,
subidor de mi infancia,
entre el barro y la niebla
que en los ojos te humillan.”
(Albán, 1995: 192)

A lo largo de todo el poema albaniano, el sujeto lírico se presenta como un buey y este, como un ser humano trágico como aquel. Simbólicamente: "la figura del buey marca la fuerza y la potencia, el poder de abrir surcos intelectuales para recibir las lluvias fecundas del cielo" (Pseudo-Dionisio 1943: 242). Así como el sujeto lírico se encuentra bajo el yugo del conocimiento racional que le impide acceder a un estado intuitivo pleno, el buey está bajo el yugo de la labranza ("entre el barro y la niebla/ que en los ojos te humillan”). Pero aun, así como el yugo simboliza para el sujeto lírico el estado de meditación y unificación con lo numinoso ${ }^{40}$, de igual manera el buey como su compañero se enfrenta a lo indeterminado, incierto y caótico de la existencia ("niebla"), (a)guardando en sus ojos también la posibilidad de reivindicación de su mundo y condición profana, simbolizada en la coincidentia oppositorum de la niebla ${ }^{41}$. Este último símbolo connota tanto la confusión en el tránsito temporal de la existencia, como el preludio de las revelaciones y manifestación sagradas $^{42}$.

No obstante, existe una significativa y rotunda diferencia entre ambos. El buey es simplemente una bestia, y el sujeto lírico, contemplándola, es capaz de trascender su propia naturaleza física al experimentar la aprehensión del mysterium tremendum et fascinas y el paso desde lo profano hacia lo sagrado; experiencias, que el buey, profundamente, no puede vivir.

En suma, el buey, en este poema albaniano, representa para el sujeto lírico el deseo por alcanzar un conocimiento a través de la intuición sobre la conciencia racional. "Se siente, así, una necesidad por el Ser desde el plano del conocimiento. Se exhorta a la defensa de una existencia trascendental en medio de las situaciones materiales y temporales cotidianas" (Campos 2012: 84).

\section{5. ¡Apadrear ${ }^{43}$ el yugo...!}

En síntesis, en textos literarios, pictóricos, plásticos y orales costarricenses redunda el imaginario colectivo de que el buey es un símbolo identitario procedente del bestiario nacional (Campos 2006, Chang 2009a, 2009b), que sugiere, remite y recuerda esa imagen paradisíaca, bucólica, idílica, pacífica, laboriosa y perfecta de Costa Rica, sus valores y tradiciones (Amoretti 1987, Rojas y Ovares 1995, Quesada 2000, 2002; Campos 2006); es decir, la concreción del arquetipo del paraíso terrenal, según el cual "la naturaleza se aparece a quienes la miran como el paraíso, como la quietud perfecta; el lugar donde el hombre hallaría el absoluto apaciguamiento" (Zambrano, 1992: 291).

Aunque esta idea idílica se concretiza en leyendas y refranes, y textos como: la estatuilla de San isidro Labrador, El moto, Juan Varela, El primo, "En Heredia", "Mercando leña”, "Romance de las carretas", "Tico", "La vaca", "Buey", "Buey negro", "Domingueando", "Camino polvoriento", "Casa típica costarricense", el Himno Nacional de Costa Rica y, a su modo, respondiendo a los ideales de la oligarquía cafetalera y el Olimpo, en "Neurosis" y El primo, una imagen más trágica y desacralizante de la bucólica (Campos 2006) se presenta en textos como: "El camino", El jaúl y "Los dos bueyes". Este giro no solo responde al cambio de óptica que tendrá el buey en la literatura, sino que también implica la nueva mirada sobre el ser costarricense: el campesino; se pasa así "de la bondad idílica a la tragedia humana" (Campos, 2006: 99).

El pathos o destino trágico del buey del texto albaniano no se circunscribe y delimita determinantemente al yugo de las labores 
agrícolas, ganaderas, comerciales o contingentes, como ocurre en el giro ofrecido por el cuento "El camino", las novelas El jaúl y El primo, así como en el poema "Los dos bueyes". Lo trágico de la figura del buey en la Enciclopedia de maravillas de Albán (1995) se orienta hacia la identificación, la mostración y la revelación de una existencia, un saber y una plenitud intuitiva $\mathrm{y}$ trascendental que involucra a todo ser humano, no únicamente a un campesino, un oligarca o un pueblo específico, en medio del yugo simbólico que es su autoconocimiento, autoidentificación, compromiso, fe y perseverancia con la empresa cotidiana de unificarse espiritualmente con lo cósmico, lo numinoso y darle respuestas a la vida, desde la vivencia plena de lo sagrado, y no solo desde la dimensión de las experiencias terrenales y profanas.

En este sentido, léanse los versos:

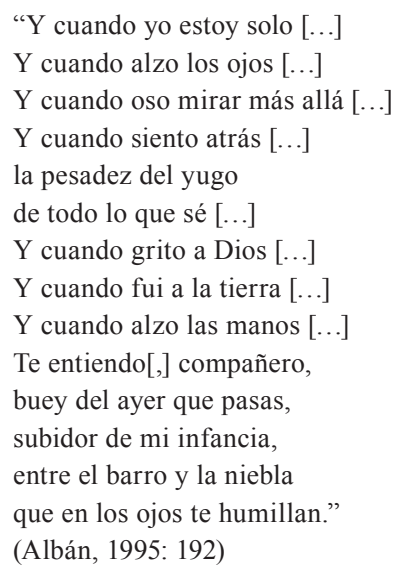

El buey albaniano es un buey trágico, no porque acepte y se someta a la adversidad de las realidades contingentes como se ha demostrado en los textos de la literatura costarricense (Campos 2012), sino porque busca cohesionar ("subidor") en su ser, como el sujeto lírico, lo profano, lo terrestre y lo racional ("barro") con lo sagrado, lo celestial e intuitivo ("más allá"). Con esto, el poema de Albán abre una nueva perspectiva poética e ideológica en torno a la figura del buey en el imaginario y la literatura costarricenses.

\section{Notas}

1. Interjección utilizada en el habla de los boyeros costarricenses para azuzar a los bueyes (Chang 2009a: 71).

2. Chang señala cinco particularidades del boyeo costarricense: "las técnicas de construcción artesanal de la carreta; la decoración multicolor de carretas y yugos, el canto de la rueda de la carreta; el boyeo, cifrado en saberes, prácticas, creencias y valores en cuanto a la selección, capada, amansamiento, cuidados y guía de la yunta de bueyes y la profusión lingüística" (2009a: 66).

3. En 2005, la "Tradición del boyero y la carreta" fue declarada por la Unesco como Obra Maestra del Patrimonio Oral e Inmaterial de la Humanidad (Chang 2009a, 2009b).

4. La oligarquía costarricense, esa "pseudonobleza criolla" (Campos 2006: 98), aglutinó la antigua élite o "aristocracia colonial" (Botey y De la Cruz 1987: 231), así como a inmigrantes y empresarios centroamericanos y europeos, campesinos cafetaleros. Sus actividades fueron la banca, el cultivo, procesamiento, exportación y comercio del café, principalmente a Gran Bretaña y Alemania; en un segundo plano, la explotación bananera y ganadera (Monge 1974, Rodríguez 1981, Botey y De la Cruz 1987).

5. Frente a una segmentación urbana, los oligarcas impulsaron una ambiciosa europeización de las políticas civilizadoras de los sectores populares, mediante la moral, el arte, la religión y la educación (Botey y De la Cruz 1987).

6. Dicho templo parroquial fue declarado Patrimonio Histórico Arquitectónico el 16 de marzo de 2007.

7. Murillo toma la cita del periódico El Ferrocarril, número 3, p. 1, del día 6 de abril de 1872.

8. El resaltado, con letra cursiva, es del investigador de este estudio.

9. Lo mismo que en la cita anterior, el resaltado es este investigador.

10. Chang (2009b) considera además el uso de la carreta en el transporte vinculado a actividades como los bautizos y nupcias. Al respecto de esta 
última actividad, acotan Zegarra y Fernández: "En un matrimonio, la novia era transportada hasta la iglesia para luego regresar a los nuevos esposos a su hogar donde se realizaba la fiesta de celebración" (2010a: §17).

11. Dicen Zegarra y Fernández: “Aquellas personas enfermas o accidentadas eran transportadas en carreta para recibir ayuda médica, al igual que mujeres con complicaciones de parto. Se colocaban unos mecates (cuerdas) entre los parales de la carreta, a forma de hamaca, donde se acuesta al paciente, aminorando el golpe del vehículo. La carreta también sirvió como carro fúnebre en los entierros" (2010a: §18).

12. Zegarra y Fernández (2010a) incluyen el arroz y el cacao, y no solo afirman la siembra y cosecha de estos productos, sino también su intercambio comercial entre ciudades y aldeas.

13. Se utilizan la carreta y los bueyes también para el transporte de leña y carbón y abastecimiento de estos a los hogares (Zegarra y Fernández 2010a).

14. Chang (2009a, 2009b) ha recolectado el léxico de los boyeros, como ejemplo de profusión lingüística dentro de los costarriqueñismos, debido al valor identitario y nacional del patrimonio cultural del boyeo.

15. Dice Campos: "En esta afirmación de lo edénico y pastoril, el Olimpo costarricense se ubica en la tradición estética y filosófica - desde Platón y Virgilio, hasta Erasmo y Goethe- que busca la inocencia perdida por la humanidad, que añora ese tiempo idílico en que la gente era ingenua y bonachona" (2006: 93).

16. En el habla de los boyeros costarricenses: "Amansado. También dícese de la vaca mansa de ordeñe". En la actualidad, tiene otro significado: reacio" (Chang, 2009a: 72).

17. "Cuchillo de labor usado en las plantaciones de café, fabricado por la casa norteamericana The Collins Company, Collinsville, Conecticut. La marca es de gran reputación - verdadero paradigma de la herramienta de acero finoque suplanta en el habla del pueblo a la palabra cuchillo" (González, 2000: 139).

18. De acuerdo con Amoretti, la palabra concho: "remite a la falta de refinamiento y la naturaleza tosca y sin pulimento del campesino" (2000: 36).
19. El hecho de que Eduardo, el hijo de Juan Varela, vaya fuera de la carreta simboliza el determinismo por herencia que debe seguir el primogénito al asumir las labores y las pertenencias del padre, las responsabilidades de un hombre de acuerdo con el discurso patriarcal tradicional, sobre todo en relación con el ser todopoderosos y proveedor de la familia (Campos 2010b). Al respecto, afirman Zegarra y Fernández: "Los bueyes y carreta también servían de adelanto de herencia a hijos varones, quienes podían comenzar a independizarse económicamente. Jóvenes familias emigraban a nuevos territorios con la ayuda imprescindible de la carreta (siglo XIX)” (2010a: §15).

20. En ocasiones: "Se colocaba un colchón en el piso de la carreta para dormir y un toldo amarrado para protegerse del sol” (Zegarra y Fernández 2010a: §23).

21. "En sus obras pronto se decantaron por un paisaje semirrural que privilegiaba la casa de adobe impecablemente encalada, hogar no lujoso de un próspero dueño" (Ulloa 2008: §6).

22. Este artista nicaragüense no fue considerado como representante de la Nueva Sensibilidad, solo porque no residía en la Meseta Central. En 1940 se muda a esta última. Hasta 1950 se reconoce el valor de su obra (Ulloa 2008).

23. De acuerdo con Fernández, esta metáfora sigue el esquema A, b, b', b"...; es decir: "Se multiplican los planos. El plano real da lugar a más de una evocación, aunque siempre referidas a dicho plano" (1972: 122).

24. Frente al estado precario de los caminos entre 1820 y 1846 , con los impuestos a las exportaciones de café, se posibilitó que: "Ya para 1889 se ha establecido una red de caminos empedrados y rodeados de cantos rodados (piedras redondeadas y lisas) adecuados para el tránsito de 1 ó 2 carretas" (Zegarra y Fernández, 2010a, §30). Durante esta segunda mitad del siglo XIX se implementó el sistema de pavimento con fragmentos de piedra y arena, sobre el cual las ruedas de las carretas provocaban ruido; esto llevó a regular las horas y formas de tránsito de las carretas por las zonas urbanas, por lo que se comenzó a desplazar las carretas a regiones rurales (Zegarra y Fernández, 2010a).

25. Al respecto, explica Campos (2006) que el buey es un toro castrado y que, por ello, no participa del 
simbolismo de "la violencia creativa indomable, la potencia sexual irresistible" (Chevalier y Gheerbrant, 1988: 1001).

26. El Olimpo fue un grupo de intelectuales, que promovieron un movimiento y desarrollo culturales en Costa Rica; entre ellos "participaron los profesores españoles (como los Fernández Ferraz) que impartían lecciones en el Colegio San Luis Gonzaga, y personalidades como Cleto González Víquez, Ascensión Esquivel, Ricardo Jiménez, Carlos Durán, Manuel de Jesús Jiménez, Ricardo Fernández Guardia, Mauro Fernández, José Astúa Aguilar, además de escritores y científicos extranjeros traídos por el gobierno de Bernardo Soto, como Henri Pittier, Juan Rudín, Pablo Biolley y muchos más” (Monge, 1974: 228).

27. Dice Monge: "En Costa Rica se supo con un poco de retraso lo que sucedía en España [...] Así, mientras nuestros hermanos de América del Sur y de México lucharon en los campos de batalla dirigidos por grandes capitanes como Bolívar, San Martín y otros más, en Costa Rica no ocurría nada. Siguieron los labriegos del Valle Central tan Pacificos como antes, sin aspiraciones, sin darse cuenta de la importancia de las guerras que se libraban muy lejos de aqui" (1974: 152). El énfasis con letra cursiva es del autor de esta investigación.

28. Amoretti acota que esta "será el entrenamiento para enfrentar la lucha en la defensa por la Patria" (1987: 44).

29. Durante la última década del siglo XIX, se gesta un sentimiento nacionalista en Costa Rica, reflejado en la emergencia de la Biblioteca Nacional (1888), la estatua del héroe nacional Juan Santammaría (1891), la polémica sobre el nacionalismo en la literatura (1894), el Monumento Nacional erigido en el Parque Nacional (1895) y el Teatro Nacional (1896).

30. Golpe infligido con un chuzo o palo armado con un pincho de hierro, que se usa para defenderse y ofender (RAE 2001).

31. Una prosopopeya se puede dar como vivificación en tanto se dota "de vida animal a algo o a alguien, sin que ello represente necesariamente una deshumanización o una animalización" (Fernández, 1972: 79).
32. Acotan Chevalier y Gheerbrant: "Si se considera, al contrario, el agua como punto de partida con su pureza original, el barro aparece como un proceso de involución, un comienzo de degradación" (1988: 179).

33. Aburrido, tonto, improductivo (Quesada 2007).

34. Recuérdese en torno a esto la polémica del nacionalismo en la literatura, entre 1894 y 1902 (Segura 1995).

35. Acción de extraer la cáscara del café (Quesada 2007).

36. Aclara Chang: "Marca con que se señala el ganado" (2009a: 71).

37. Para una lectura más profunda del análisis de este poema albaniano, léase mi tesis de grado: De la permanencia de lo sagrado en la Enciclopedia de maravillas de Laureano Albán (2012).

38. Fernández (1972) define la conversión como una figura de dicción al darse la repetición de la frase, al estilo de la anáfora, o de la estructura sintáctica, la cual presenta un cambio al final del verso.

39. En la edición de este poema, en el tomo I de la Enciclopedia de maravillas, se omite el uso de la coma para aislar el vocativo (RAE, 2011). Para efectos de este estudio, se procede a agregarla entre corchetes

40. La palabra numen proviene de la voz latina: numen, -inis, la cual significa: "poder divino, providencia, gobierno de Dios; divinidad, majestad, alteza divina" (Vox, 2002, p. 294).

41. Afirman Chevalier y Gheerbrant: "se considera la niebla predecesora de las revelaciones importantes: es el preludio de la manifestación" (1988, p. 752).

42. Se entiende por sagrado: "Este se entenderá como la emoción, la experiencia religiosa, que provoca, en el ser humano, una manifestación plenaria y cósmica del Ser supremo o la divinidad, la potencia por excelencia. Esta es una manifestación de orden totalmente diferente al de las realidades y objetos naturales y profanos del mundo fenomenológico; es cuanto Eliade (1981) define como ganz andere: algo radical y completamente diferente de lo humano o cualquier ser terrenal. De ahí que: «Lo sagrado es un tipo particular del proceso creador del hombre, 
por medio del cual manifiesta un modo de ser, de obtener una posición concreta en el mundo, radicalmente diferente de la existencia profana» (von Mayer, 1999, p. 117)" (Campos, 2012: 49).

43.

Dice Chang: "«apadrear», que, en Juan Viñas de Cartago, se refiere a formar una yunta, con un buey manso y uno chúcaro" (2009a: 73).

\section{Bibliografía}

Albán, Laureano. 1995. Enciclopedia de maravillas. Tomos I. Pittsburg, Estados Unidos: International Poetry Forum.

Amoretti, María. 1987. Debajo del canto. San José: EUCR.

2000. "Dos momentos, dos autores en la historia de una literatura". En Filología y Lingüistica, XXVI (2): 27-38.

Amighetti, Francisco. s.f. "En Heredia". http:// www.franciscoamighetti.com/literatura/ francisco_costarica/26.htm

Anónimo. s.f. "La carreta sin bueyes, versión A". http://www.guiascostarica.com/mitos/ mitos01.htm

Arana, Gonzalo. 2011. "Casa típica costarricense". http://pintandocostarica.blogspot. com/2011/04/casa-tipica-costarricensepintura-al.html

Botey, Ana y Vladimir de la Cruz. 1987. Historia general de Costa Rica. Barcelona: Euroamericana de Ediciones.

Campos, Melvin. 2006. "La transformación de una identidad o cómo lanzar una vaca del Olimpo”. En Káñina, XXX (2): 91-101.

Campos, Ronald. 2012. De la permanencia de lo sagrado en la Enciclopedia de maravillas de Laureano Albán. Tesis de Maestría. Universidad de Costa Rica.

Chang, Giselle. 2009a. “ ¡Jesa buey! Habla del boyero: Un ejemplo de diversidad cultural”. En Herencia, 22 (2): 65-76.

2009b. "Costarriqueñismos en el léxico del boyeo". En Káñina, 33 (Especial): 107117.

Chavarría, Lisímaco. 2003. Manojo de guarias. San José: EUNED.

Chen, Jorge. 2007. Del sosiego luminoso y serenidad metafísica en Mariana Sansón Argüello. León, Nicaragua: Editorial Universitaria UNAN.

Chevalier, Jean y Alain Gheerbrant. 1988. Diccionario de los símbolos. Barcelona: Herder.

Cardona, Jenaro. 2011. El primo. San José: EUNED.

Echeverría, Aquileo. 1998. Concherías. San José: EUNED.

Fernández, Pelayo. 1972. Estilística. Madrid: Porrúa.

Fernández, Ricardo. 2004. Hojarasca. San José: EUNED.

Gagini, Carlos. 2006. Vagamunderías y otros poemas. San José: EUCR.

García, Joaquín. 2001. El moto. San José: Lehmann.

González, Ana. 2007. Historia general del arte. San José: EUNED.

González, Manuel. 2000. La propia y otros cuentos. San José: EUNED. 
Herrera, Adolfo. 2000. Juan Varela. San José: Editorial Costa Rica.

Jiménez, Max. 1998. El jaúl. Heredia: EUNA. 2000. Toda la poesía 1929-1936. Heredia: EUNA.

Jones, Sonia. 2005. "El lexema «angustia» en un corpus de la literatura costarricense". En Filología y Lingüística, XXXI (1): 51-56.

Marchena, Julián. 1989. Alas en fuga. San José: Editorial Costa Rica.

Monge, Carlos. 1974. Historia de Costa Rica. San José: Trejos.

Morales, Orlando. 1986. "Trapiches hidráulicos en Costa Rica”. En Filosofía, XXIV (59): 111-116.

Murillo, Carmen. 1995. Identidades de hierro y humo. La construcción del ferrocarril al Atlántico 1870-1890. San José: Porvenir.

Pseudo-Dionisio, Areopagita. 1943. Obras completas. París: Montaigne.

Quesada, Álvaro. 2000. “«El primo» de Jenaro Cardona: variaciones sobre el tema de la modernidad en el San José finisecular". En Diálogos Revista Electrónica de Historia, 1(2): 1-33.

2002. Uno y los otros. San José: EUCR.

Real Academia Española. 2001. Diccionario de la lengua española. [Versión electrónica]. http://www.rae.es/rae.html

2010. Nueva gramática de la lengua española: Manual. España: Espasa Libros.
Rodríguez, Eugenio. 1981. Biografía de Costa Rica. San José: Editorial Costa Rica.

Rojas, Margarita y Flora Ovares. 1995. 100 años de literatura costarricense. San José: Farben.

Salazar, Carlos. 1990. Cuentos de angustias y paisajes. San José: El bongo.

Segura, Alberto. 1995. La polémica (1894-1902): El nacionalismo en literatura. San José: EUNED.

Stewart, WATT. 1967. Keith y Costa Rica. San José: Editorial Costa Rica.

Ulloa, Édgar. 22 de junio 2008. "El campo de la luz”. En La Nación. Recuperado de http:// wvw.nacion.com/ancora/2008/junio/22/ ancora1587363.html.

Vox. 2002. Diccionario esencial latino. Barcelona: SPES.

Zambrano, María. 1992. El hombre y lo divino. Madrid: Ediciones Siruela.

Zegarra, Carlos y Carlos Fernández. (30 de noviembre 2010a,). "Cargando la nueva República”. http:// costaricaexplorerguide.com/php/ editorial.php?idm=1\&editorial=199\&df panel $=0 \& m e n u=2$.

(30 de noviembre 2010b). "La carreta en el siglo XX". http:// costaricaexplorerguide.com/php/ editorial.php?idm=1\&editorial $=199 \& \mathrm{df}$ panel $=0 \&$ menu $=3$. 
